\title{
UMA NOVA ABORDAGEM EM EDUCAÇÃO AMBIENTAL NA RESTINGA DE MARICÁ, RJ - BRASIL
}

\author{
Alexandre Verçosa Greco ${ }^{1}$ \\ Ana Tereza Araujo Rodarte ${ }^{2}$ \\ Ana Angélica Monteiro de Barros ${ }^{3}$ \\ Heloísa Alves de Lima Carvalho ${ }^{4}$ \\ Maria Célia Rodrigues Correia ${ }^{5}$ \\ Patrick de Oliveira ${ }^{6}$
}

\section{Resumo}

As restingas são ecossistemas litorâneos ameaçadas de extinção devido à sua degradação decorrente da privatização de áreas públicas, implantação de loteamentos e condomínios, além de grandes projetos turísticos. Devido aos problemas ambientais ocorrentes na restinga, faz-se necessário associar a pesquisa acadêmica à educação ambiental como ferramenta de ensino para conscientizar a preservação desse ambiente. Nesse tipo de ambiente as Myrtaceae destacam-se nas restingas do estado do Rio de Janeiro pela sua riqueza de espécies. Estudos de biologia floral são importantes para a compreensão da dinâmica dos ecossistemas, uma vez que a pesquisa fenológica permite, por exemplo, estabelecer o período em que os recursos vegetais estão disponíveis para a fauna. O objetivo do trabalho foi integrar dos dados gerados na pesquisa fenológica com plantas da família Myrtaceae na Restinga de Maricá com as atividades desenvolvidas na educação ambiental junto às escolas públicas desse município. A pesquisa desenvolveu-se na Área de Proteção Ambiental da Restinga de Maricá (RJ), ao longo de um transecto de $500 \mathrm{~m}$ sobre o cordão arenoso interno. Foram observadas em campo doze espécies de Myrtaceae quanto à floração com maior intensidade na estação quente e chuvosa e disponibilidade de frutos ao longo de todo ano. As atividades de educação ambiental foram realizadas com alunos que visitaram a restinga utilizando a Trilha do Barco e a cartilha como matéria de apoio, onde redigiram uma redação abordando os objetivos da Carta de Belgrado. Todos os estudantes consideraram positiva a experiência na restinga, onde percebeu-se que a maioria dos alunos ficou sensibilizada, como observado em suas expressões na aula de campo e nas redações produzidas. A utilização de ambientes naturais para aulas em trilhas interpretativas e a produção de cartilhas com informações dessas regiões, mostram-se importantes ferramentas didáticas para práticas de educação ambiental. $\mathrm{O}$ trabalho mostrou a importância em associar a pesquisa acadêmica às atividades de educação.

Palavras-chave: Biologia floral; Myrtaceae; trilha interpretativa

\footnotetext{
${ }^{1}$ Professor do Colégio Estadual Maria Zulmira Tôrres - ale_vercosagreco@ hotmail.com

${ }^{2}$ Museu Nacional/UFRJ, LABFLOR - atrodarte@gmail.com

${ }^{3}$ Faculdade de Formação de Professores da UERJ, DCIEN, GEIA - anaangbarros@gmail.com

${ }^{4}$ Museu Nacional/UFRJ, LABFLOR - heloisa.alc@gmail.com

${ }^{5}$ Museu Nacional/UFRJ, LABFLOR - maria.celia.rodrigues.correia@gmail.com

${ }^{6}$ Professor do Colégio Estadual Sol Nascente - patrickoliveira_401@ @otmail.com
} 


\begin{abstract}
The salt marshes are coastal ecosystems endangered due to their degradation, resulting from the privatization of public areas, implementation of subdivisions and condominiums, and large tourism projects. Due to environmental problems occurring in the sandbank, it is necessary to link academic research to environmental education as a teaching tool to educate the preservation of that environment. In such an environment the Myrtaceae stand out in the marshes of the state of Rio de Janeiro for their species richness. Floral biology studies are important in understanding the dynamics of ecosystems, since the search phenological allows, for example, to establish the period of plant resources available for wildlife. The objective was to integrate the data generated in phenological research with plants in the family Myrtaceae in Restinga de Marica for the activities of environmental education in the public schools of this county. The research was developed in the Environmental Protection Area of Restinga de Marica (RJ) along a transect of $500 \mathrm{~m}$ on the sandy barrier internal field were observed in twelve species of Myrtaceae as flowering with greater intensity in the hot, rainy season and fruit availability over the entire year. The environmental education activities were conducted with students who visited the sandbank using the track of the boat and the booklet as a matter of support, which wrote an essay addressing the objectives of the Charter of Belgrade. All students considered positive experience in the sandbank, where it was noticed that most of the students were appreciative, as noted in their expressions in class and field in their newsrooms. The use of natural environments for classes in interpretive trails and production of booklets with information from these regions, appear important teaching tools for environmental education practices. The study showed the importance of associating academic research education activities.
\end{abstract}

Keywords: Floral biology, Myrtaceae, interpretative trail

\title{
Introdução
}

Os ecossistemas de restinga são constituídos por diferentes comunidades biológicas que ocupam os depósitos arenosos paralelos à linha da costa, cujas formas são, em geral, alongadas e resultantes de processos de erosão e sedimentação. A cobertura vegetal ocorre em mosaico e distribui-se em praias, cordões arenosos, dunas e depressões, apresentando, de acordo com o estágio sucessional, estrato herbáceo, arbustivo e arbóreo (CONAMA, 2002).

As restingas são ecossistemas litorâneos altamente ameaçados devido à sua degradação decorrente da privatização de áreas públicas, implantação de loteamentos e condomínios, além de grandes projetos turísticos (HOLANDA, 1988). A Restinga de Maricá (RJ) se integra nesse contexto, sendo que o presente estudo sobre a fenologia de plantas da restinga, associado à educação ambiental, contribui gerando subsídios para projetos de conservação ambiental.

A fenologia é o campo da pesquisa baseado nas observações de eventos biológicos repetitivos com base na reprodução de plantas e a relação com mudanças que ocorrem no meio biótico e abiótico (MORELLATO; LEITÃO-FILHO, 1990). A fenologia é de extrema importância para a compreensão dos ecossistemas florestais, para o entendimento dos diferentes processos de reprodução das plantas e regeneração dos ambientes. Além disso, 
permite estabelecer a época em que os recursos vegetais (como folhas, flores, frutos e sementes) estão disponíveis aos animais da comunidade (STAGGEMEIER et al., 2007).

Na flora das restingas do estado do Rio de Janeiro destaca-se a família Myrtaceae pela alta riqueza de espécies (ARAUJO, 2000). Suas flores reúnem-se em inflorescências axilares e, às vezes paniculadas, apresentando cores predominantemente claras, raramente vermelhas; são hermafroditas, com simetria radial, apresentando numerosos estames livres de deiscência rimosa, raramente poricida; com ovário ínfero (STAGGEMEIER et al., 2007; WILSON et al., 2005). Os frutos são carnosos, do tipo drupa e de cores variadas quando maduros, dependendo da espécie (PIZO, 2002).

Integrando os estudos referentes à fenologia de Myrtaceae a outros campos da ciência, o presente trabalho apresenta a experiência da associação entre ensino, pesquisa e extensão, áreas que estão estreitamente relacionadas e que serão ferramentas para promover e estimular a conscientização de conservação e preservação da Área de Proteção Ambiental (APA) da Restinga de Maricá. Essa é uma forma de transferir conhecimentos estritamente acadêmicos para uma linguagem passível de ser usada em atividades de educação ambiental.

A importância da compreensão do ambiente da restinga exige uma necessidade de articular modalidades do processo educativo. Para isso, duas referências legais foram consideradas: artigo $1^{\circ}$ da Lei n ${ }^{\circ} 9.795$ de 1999 da Política Nacional de Educação Ambiental (PNEA) (BRASIL, 1999), “entende-se por Educação Ambiental os processos dos quais o indivíduo e a coletividade constroem valores sociais, conhecimentos, habilidade, atitudes e competências voltadas para a conservação do meio ambiente, bem de uso comum do povo, essencial a sadia qualidade de vida e sua sustentabilidade". O artigo $2^{\circ}$ da referida lei considera "Educação Ambiental como componente essencial e permanente da educação nacional, devendo estar presente de forma articulada, em todos os níveis e modalidades do processo educativo, em caráter formal e não formal" (BRASIL, 1999).

Segundo Holanda (1988), devido aos problemas ambientais ocorrentes na restinga, é importante e urgente abordar a educação ambiental no processo educativo formal, nos vários níveis de ensino, e no não formal. Desta forma, os autores do presente estudo propõem a elaboração de uma cartilha ambiental com linguagem fácil e que mencione os problemas ambientais que ocorrem nestes ecossistemas. Além da cartilha, outra ferramenta de apoio à educação ambiental é a utilização de trilhas interpretativas (ROBIM; TABANEZ, 1993; MENGHINI, 2005; CURADO; ANGELINI, 2006). O uso de trilhas para a interpretação de áreas naturais tem sido frequentemente recomendado por oferecer oportunidades de contato direto com o ambiente natural, direcionado ao aprendizado e à sensibilização (CURADO; ANGELINI, 2006). Sendo assim, a interpretação em áreas naturais é uma estratégia educativa que associa o ser humano com a natureza, motivando-o a contribuir para a preservação das Unidades de Conservação (ROBIM; TABANEZ, 1993).

O objetivo desse trabalho é a integração dos dados gerados na pesquisa fenológica com plantas da família Myrtaceae na Restinga de Maricá com as atividades desenvolvidas na educação ambiental junto às escolas públicas desse município. Como estratégia foi elaborada 
uma cartilha ambiental com linguagem acessível ao público alvo, sendo esta aplicada a uma trilha interpretativa.

\section{Materiais e métodos}

O estudo foi desenvolvido na APA da Restinga de Maricá (RJ) $\left(22^{0} 53^{\prime}\right.$ 'S $-22^{0} 52^{\prime}$ 'S e $42^{0} 52^{\prime}-42^{0} 51^{\prime} \mathrm{W}$ ), localizada a cerca de $50 \mathrm{~km}$ do município do Rio de Janeiro (SILVA; OLIVEIRA, 1989). A Restinga de Maricá apresenta uma área de $20,7 \mathrm{~km}^{2}$, entre a Ponta do Alto Mourão e Ponta Negra (ARAUJO; MACIEL, 1998). O clima é classificado por Köppen (KOTTEK et al., 2006) como AW tropical chuvoso, com chuvas concentradas no verão e reduzidas no inverno.

Para o estudo fenológico foram observados 104 indivíduos de doze espécies de Myrtaceae (Calyptranthes brasiliensis Spreng., Eugenia selloi B.D. Jacks., Eugenia umbelliflora O. Berg, Myrcia bergiana O. Berg, Myrcia ilheosensis Kiaersk, Myrcia lundiana Kiaersk, Myrcia multiflora (Lam.) DC., Myrcia racemosa (O. Berg) Kiaersk, Myrcia vittoriana Kiaersk, Myrciaria floribunda (H. West ex Willd.) O. Berg, Myrrhinium atropurpureum Schott e Neomitranthes obscura (DC.) N. Silveira), presentes na Restinga de Maricá (RJ). Foram coletadas plantas férteis (com flores e/ou frutos) de cada espécie como material testemunho ao longo do período de estudo. Essas amostras foram herborizadas segundo técnicas usuais utilizadas em inventários florísticos (GUEDES-BRUNI et al., 2002). As exsicatas foram incorporadas aos Herbários da Faculdade de Formação de Professores da UERJ (RFFP), Museu Nacional (R) e Jardim Botânico do Rio de Janeiro (RB).

Para cada espécie foram marcados, quando possível, 15 indivíduos com placas metálicas numeradas, ao longo de um transecto de $500 \mathrm{~m}$, dividido em 50 parcelas de $10 \mathrm{x}$ 10m (RODARTE, 2008). Os indivíduos marcados foram observados semanalmente, anotando-se dados das fenofases de floração e frutificação no período de agosto de 2009 a julho de 2011.

A segunda etapa do trabalho envolveu a elaboração de uma cartilha enfocando os conceitos básicos sobre restinga e suas plantas, apresentando os dados obtidos sobre a biologia floral das Myrtaceae numa linguagem acessível ao público envolvido. Além da parte conceitual, a cartilha possui ilustrações do ambiente da restinga e das plantas que ocorrem ao longo da trilha interpretativa (GRECO; RODARTE; BARROS, 2011). A confecção da cartilha teve como ponto de partida o diagnóstico realizado com os alunos do Colégio Estadual Elisiário da Matta através de um questionário, cujos dados não foram publicados.

A trilha interpretativa foi estabelecida a partir de um caminho já existente na Restinga de Maricá, iniciando o trajeto a partir da Laguna de Maricá até o oceano (Trilha do Barco). Essa trilha passa pelas diferentes fitofisionomias da restinga, apresentando várias espécies de Myrtaceae, algumas das quais não foram enfocadas no estudo da biologia floral.

Vinte alunos que participaram da sensibilização inicial foram levados à restinga com apoio logístico fornecido pela Secretaria de Educação da Prefeitura Municipal de Maricá. A cartilha sobre a Restinga de Maricá foi apresentada ao grupo e utilizada ao longo da trilha 
interpretativa. Durante a caminhada foram abordados os seguintes temas: a) formação da Restinga de Maricá; b) características das formações vegetais; c) informações ecológicas e biológicas das espécies vegetais; d) o papel da vegetação na conservação do ecossistema de restinga; e) os problemas ambientais ocorrentes no local.

Com o término dessa atividade, os alunos foram avaliados através de uma redação, com enfoque no que foi apresentado. A análise de conteúdo baseou-se nos objetivos da Educação Ambiental definidos pela Carta de Belgrado em 1975 (consciência, conhecimento, atitude, competências, capacidade de avaliação, participação) (REIGOTA, 1994).

\section{Resultados e discussão}

\section{a) Fenologia}

Durante o período de estudo observou-se que sempre há espécies de Myrtaceae emitindo botões e/ou flores ao longo do ano. A maioria exibiu períodos de emissão de botões e floração na estação mais quente e úmida (outubro a março): Calyptranthes brasiliensis, Myrcia ilheosensis, Myrcia vittoriana, Myrcia racemosa, Myrcia multiflora, Myrcia bergiana, Eugenia selloi e Myrciaria floribunda, mostrando que este grupo segue o padrão fenológico de floração encontrado por Rodarte (2008) para essa comunidade na Restinga de Maricá. A floração predominante nesta estação foi observada por Gressler (2005) para Myrtaceae em Floresta Atlântica no município de Sete Barras, São Paulo.

Morellato (1991) sugere que a floração seria desencadeada pelo aumento do fotoperíodo, temperatura e umidade na transição da estação seca para a úmida. A disponibilidade de luz, a quantidade de nutrientes disponíveis para plantas e a atividade dos polinizadores são maiores na estação quente e úmida, sendo assim o florescimento nesse período seria vantajoso (MORELLATO, 1992).

O desenvolvimento dos frutos foi observado para todas as espécies ao longo do ano, porém, em períodos distintos, dependendo da espécie. Para Morellato et al. (2000), ambientes com baixa sazonalidade climática podem oferecer condições pouco restritivas para o desenvolvimento dos frutos ao longo do ano.

Calyptranthes brasiliensis e Eugenia umbelliflora frutificaram e liberaram as sementes na estação fria e seca. Eugenia selloi frutificou na transição (fria-quente) e liberou sementes na estação quente e úmida. Myrcia ilheosensis e Myrcia vittoriana iniciaram o desenvolvimento dos frutos na estação quente e úmida e liberaram sementes na estação fria e seca, ocorrendo o oposto com Myrrhinium atropurpureum. Myrciaria floribunda desenvolveu os frutos a partir da estação quente e liberou as sementes na transição fria-quente. Neomitranthes obscura iniciou a frutificação na estação fria e disponibilizou as sementes a partir da transição entre as estações fria e quente (Figura 01). 
$\left({ }^{\circ} \mathbf{C}\right)$

$(\mathbf{m m})$

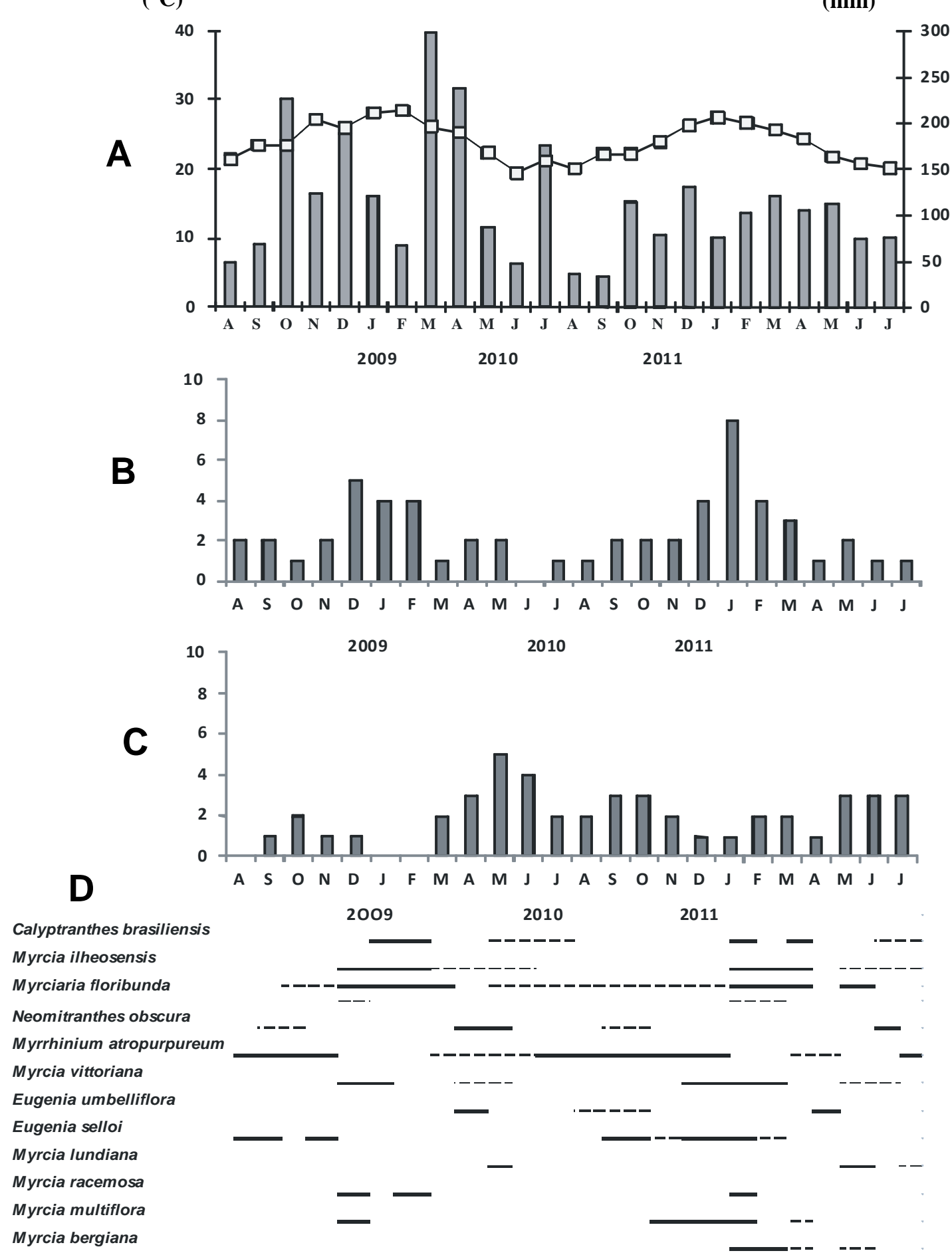

Figura 01. Eventos fenológicos floração e frutificação para as espécies de Myrtaceae no período de agosto de 2009 a julho de 2011 na Restinga de Maricá (RJ). A) Temperatura $\left({ }^{\circ} \mathrm{C}\right)$ e precipitação (mm) para a região de Maricá; B) $\mathrm{N}^{\circ}$ de espécies em floração; C) $\mathrm{N}^{\circ}$ de espécies em frutificação; D) representação esquemática dos períodos de floração (linha contínua) e frutificação (linha pontilhada) das espécies de Myrtaceae. 


\section{b) Educação Ambiental}

Os alunos ao visitarem a APA se sensibilizaram com a beleza do local e da vegetação. Pádua e Tabanez (1997 apud Curado; Angelini, 2006), relatam que aulas de campo são um instrumento eficiente para aproximar a relação do homem com a natureza, porém existe carência de estudos que comprovem a validade educacional das atividades de campo. Entretanto, Clini; Figueiredo; Figueiredo (2001) apresentaram resultados positivos em sua pesquisa, já que a percepção e o interesse sobre os problemas ambientais aumentaram.

Por se estender em diferentes formações de restinga, a Trilha do Barco foi uma excelente ferramenta para a aula. Os alunos puderam observar e tocar nos elementos naturais daquele ecossistema. Alguns conheceram folhas com galhas ${ }^{7}$, algo que nunca viram e acharam aquela estrutura estranha e, ao mesmo, tempo curiosa. A curiosidade foi observada em suas expressões nas aulas de campo e nos conteúdos das suas redações.

A cartilha foi outra ferramenta que auxiliou nas explicações sobre o ecossistema visitado. As imagens e informações textuais contidas no material didático funcionaram como elemento de apoio nos momentos das explicações.

De modo geral a atividade obteve resultado positivo, principalmente, devido à análise das redações, onde todos os estudantes aprovaram a aula de campo.

Foram destacadas algumas respostas contidas nas redações dos alunos, a partir dos questionamentos apresentados na cartilha e que são apresentadas abaixo:

1- O seu pensamento sobre a restinga antes de visitar a trilha e após a visita. Nesse caso, foram analisados dois objetivos da Carta de Belgrado: a conscientização e o conhecimento.

Aluna A: "Eu pensava que a restinga era só mato que não tinha nada de interessante, mas depois que eu conheci e percebi que tem muitas coisas que ninguém fala como: vários tipos de plantas e o clima".

2- Os problemas ambientais existentes na APA (ameaças que possam degradá-la) e seu posicionamento em relação a eles. Foram analisados neste assunto o conhecimento, atitudes e competências acerca dos problemas ambientais do local.

Aluna F: “...mas chegando lá e tendo explicações sobre a mesma, pude perceber que a restinga tem um papel muito importante para nossa cidade e todos os cidadãos que inconsequentemente não cuidam da APA, muito pelo contrário, acabam destruindo, maltratando e poluindo essa nossa riqueza."

\footnotetext{
7 Galhas, bugalhos, cecídios ou cecídias são estruturas que se originam em determinado órgão de uma planta através de hipertrofia e hiperplasia (Anatomia vegetal) de tecidos, inibição do desenvolvimento ou modificação citológica e/ou histoquímica em resposta ao ataque de organismos indutores que podem ser vírus, bactérias, fungos, nematódeos, ácaros ou insetos - parasitas, geralmente específicos à espécie (ou ao gênero ou família) da planta. Ás vezes, são estruturas comparadas aos tumores.(Fonte: Wikipédia)
} 
3- Como você contribuiria para preservar o ambiente. Neste item analisou-se a atitude, competência e participação dos alunos.

Aluna H: "Poderia fazer um parque natural colocar algumas coisas diferentes para que chame atenção dos turistas e sirva para visitas. A variedade de plantas que tem lá é bem interessante também."

4- Opine sobre a atividade. (O que você gostou e o que não gostou). Dê sugestões: No último assunto abordado foram analisadas as atitudes, competências, capacidade de avaliação e participação.

Aluna L: "Achei muito educativo, um passeio que guardarei para toda minha vida. Toda aprendizagem nele adquirida poderei passar a diante principalmente quando eu for lecionar, passarei para meus alunos. Gostei praticamente de tudo, só o que não me agradou foi à aluna (o) que teve a infelicidade de jogar um copo e o fato de muitos não terem aproveitado o passeio não só como divertimento mais principalmente como uma lição de vida. Sugiro que façam com que outras pessoas tenham o mesmo privilégio que eu e que possam ter mais placas, panfletos etc. como meio de informação sobre a importância de nossa restinga."

Entre os diversos relatos feitos pelos alunos após a visita de campo, o trecho redigido pela aluna "D" mostra a importância desta atividade:

"Eu já tinha noção da grande importância da restinga, porém ao ir lá pude ter a oportunidade de até tocar em certas plantas aumentou em minha mente a necessidade de melhorar minhas atitudes em relação à natureza".

\section{Conclusões}

Conforme redigido nas redações, após visita à Trilha do Barco, os estudantes demonstraram interesse pelo ecossistema local, entusiasmo e encantamento com a aula no campo, além da preocupação com os problemas ambientais da Restinga de Maricá. O apoio da cartilha para interpretar os elementos da APA em estudo, foi fundamental para a prática de campo. Como as espécies de Myrtaceae não estavam em período de floração, os alunos observaram as imagens de flores e frutos naquele material didático, além das informações fenológicas, distribuição, uso entre outros. Logo, a utilização de ambientes naturais para aula e a produção de cartilhas com informações dessas regiões, mostraram-se importantes ferramentas didáticas para práticas de educação ambiental.

Apesar dos estudantes apresentarem propostas e demonstrarem que foram sensibilizados, a obtenção de resultados eficientes de conscientização a partir das atividades de educação ambiental depende de um processo contínuo e não pontual. Portanto, esse estudo mostra a importância em associar a pesquisa acadêmica às atividades de educação. $\mathrm{O}$ trabalho 
continuado e transdisciplinar ofereceu aos alunos maior tempo de vivência, que poderá contribuir, de fato, em mudanças de valores e comportamento.

\section{Referências bibliográficas}

ARAUJO, D. S. D. Análise florística e fitogeográfica das restingas do estado do Rio de Janeiro. Rio de Janeiro. Tese (Doutorado em Geografia). Universidade Federal do Rio de Janeiro. 169 p., 2000.

ARAUJO, D. S. D.; MACIEL, N. C. Restingas fluminenses: Biodiversidade e preservação. Boletim FBCN, n. 25, p. 27-51, 1998.

BRASIL. LEI N. ${ }^{\circ} 9.795$ de 1999. Política Nacional de Educação Ambiental. Dispõe sobre a educação ambiental. Institui a política nacional de educação ambiental e dá outras providências. 1999. Disponível em:

<http://www.presidencia.gov.br/CCIVIL/LEIS/L9985.htm >. Acesso em: 13 dez.2011.

CLINI, C. T.; FIGUEIREDO, R. M.; FIGUEIREDO, R. A. Avaliando uma ação de educação ambiental: mudança de valores e atitudes a longo prazo. Argumento, v. 3, n. 6, p. 30-36, 2001.

CONAMA. Resolução N. ${ }^{\circ}$ 303, de 20 de março de 2002. Dispõe sobre parâmetros, definições e limites de Áreas de Preservação Permanente. 2002.

CURADO, P.M.; ANGELINI, R. Avaliação de atividade de educação ambiental em trilha interpretativa, dois a três anos após sua realização. Acta Scientiarum; Biological Sciences, v. 28, n. 4, p. 395-401, 2006.

GRECO, A. V.; RODARTE, A. T. R.; BARROS, A. A. M. Restinga de Maricá. Uma nova trilha na educação ambiental. Faculdade de Formação de Professores/UERJ, 39 p., 2011.

GUEDES-BRUNI, R. R. et al. Inventário florístico. In: SYLVESTRE, L. S.; ROSA, M. M. T. (Ed). Manual metodológico para estudos botânicos na Mata Atlântica. Seropédica: Ed. Universidade Rural, p. 24-50, 2002.

HOLANDA, P. C. Conservação dos ecossistemas litorâneos. In: "Workshop" Nacional de educação para o meio ambiente. Ceará, 1988.

KOTTEK, M. et al. World map of the Köppen-Geiger climate classification updated. Meteorologische Zeitschrift, v. 15, p. 259-263, 2006.

MENGHINI, F. B. As trilhas interpretativas como recurso pedagógico: caminhos traçados para a educação ambiental. Dissertação de mestrado. Universidade do Vale do Itajaí, Itajaí, SC. 103 p., 2005.

MORELLATO, L. P. C.; LEITÃO-FILHO, H. F. Estratégias fenológicas de espécies arbóreas em floresta semidecídua na Serra do Japí, Jundiaí, São Paulo. Revista Brasileira de Biologia, v. 50, n.1, p. 163-173, 1990.

MORELLATO, L. P. C. Estudo da fenologia de árvores, arbustos e lianas de uma floresta semidecídua no sudeste do Brasil. 176 p. Tese (Doutorado em Botânica)- Universidade Estadual de Campinas, Campinas, 1991.

MORELLATO, L. P. C. Sazonalidade e dinâmica dos ecossistemas florestais na Serra do Japi. In: MORELLATO, L.P.C. (Org.). História natural da Serra do Japi: ecologia e 
preservação de uma área florestal no sudeste do Brasil. Campinas: Editora da UNICAMP, 1992. p. $98-110$.

MORELLATO, L. P. C et al. Phenology of Atlantic rain forest trees: a comparative study. Biotropica, v. 32, n. 4B, p. 811-823, 2000.

PIZO, M. A. The seed dispersers and fruit syndromes of Myrtaceae in Brazilian Atlantic Forest. In: LEVEY, D.J.; SILVA, W.R. ; GALETTI, M. (Ed.). Frugivores and seed dispersers: biodiversity and conservation perspectives. Wallingford: CABI Publishing ,2002. p. 129-143.

REIGOTA, M. O que é Educação Ambiental. São Paulo: Ed. Brasiliense, 1994.107 p.

ROBIM, M. J.; TABANEZ, M. F. Subsídios para implantação da trilha interpretativa da Cachoeira-Parque Estadual de Campos do Jordão. Revista do Instituto Florestal, v. 5, n. 1, p. 65-89, 1993.

RODARTE, A. T. R. Caracterização espacial, temporal e biologia floral das espécies de restinga, com ênfase nos recursos florais. 189 p. Tese (Doutorado em botânica)- Museu Nacional/UFRJ, Rio de Janeiro, 2008.

SILVA, J. G.; OLIVEIRA, A. S. A vegetação de restinga no município de Maricá-RJ. Acta Botanica Brasilica, v. 3, n. 2, p. 253-272, 1989.

STAGGEMAIER, V. G.; MORELLATO L. P. C.; GALETTI, M. Fenologia reprodutiva de Myrtaceae em uma ilha continental de Floresta Atlântica. Revista Brasileira de Biociências, v. 5, p. 423-425, 2007.

WILSON, P. G. et al. Relationships within Myrtaceae sensu lato based on a matK phylogeny. Plant Systematics and Evolution, v. 251, p. 3-19, 2005. 